\title{
Substituição da Proteína do Farelo de Soja pela Proteína do Farelo de Canola em Dietas para a Tilápia do Nilo (Oreochromis niloticus) na Fase de Crescimento

\author{
Claudemir Martins Soares ${ }^{1}$, Carmino Hayashi², Anna Christina Esper Amaro de Faria1, \\ Wilson Massamitu Furuya ${ }^{3}$
}

\begin{abstract}
RESUMO - Este experimento foi realizado com o objetivo de avaliar os efeitos de diferentes níveis de substituição da proteína do farelo de soja (FS) pela proteína do farelo de canola (FC) sobre o desempenho e características de carcaça da tilápia do Nilo (Oreochromis niloticus), na fase de crescimento. Foram utilizados 80 peixes $(22,19 \pm 0,29 \mathrm{~g})$ distribuídos em um delineamento em blocos casualizados, com quatro tratamentos e cinco repetições. As dietas foram formuladas de forma a terem níveis de 0,$00 ; 33,33 ; 66,67$ e $100,00 \%$ de substituição da PB do FS pela PB do FC, correspondendo a 0,00; 24,50; 49,00 e 73,50\% de inclusão do FC nas dietas. Observou-se efeito quadrático dos níveis de substituição sobre o ganho de peso e rendimento de carcaça. A conversão alimentar aparente e a taxa de eficiência protéica não foram afetadas pela inclusão do FC nas dietas. Concluiu-se que o FC pode ser incluído em até 35,40\% da dieta, substituindo $48,17 \%$ da PB do FS em dietas para a tilápia do Nilo, na fase de crescimento.
\end{abstract}

Palavras-chave: desempenho, farelo de canola, Oreochromis niloticus, tilápia do Nilo, proteína

\section{Replacement of Soybean Meal Protein by Canola Meal Protein in Diets for Nile Tilapia (Oreochromis niloticus) in the Growing Phase}

\begin{abstract}
This experiment was carried out to evaluate the effect of diets with different crude protein (CP) replacement levels of soybean meal (SBM) by canola meal (CM) on growing Nile tilapia (Oreochromis niloticus) performance and carcass characteristics. Eighty fishes $(22.19 \pm 0.29 \mathrm{~g})$ were assigned to a block randomized design, with four treatments and five replications. The experimental diets were formulated with $0.00,33.33,66.67$ and $100.00 \%$ levels of SBM protein replacement by the CM protein, corresponding to $0.00,24.50,49.00$, and $73.50 \%$ dietary CM inclusion in the diets. It was observed effect of inclusion levels on weight gain and carcass yield. Apparent feed:gain ratio and protein efficiency rate were not affected by the treatments. It was concluded that the CM can be included at $35.40 \%$ of diets, substituting $48.17 \%$ of SM protein in diets for Nile tilapia in the growing phase.
\end{abstract}

Key Words: canola meal, Nile tilapia, Oreochromis niloticus, performance, protein

\section{Introdução}

A tilápia do Nilo (Oreochromis niloticus) é empregada em diversos sistemas de criação em um grande número de países tropicais e subtropicais, sendo uma das espécies mais importantes na aquicultura mundial (LOVSHIN, 1997). Sua produção anual vem crescendo a uma taxa e $12,00 \%$ (EL-SAYED, 1999).

Os custos com a alimentação na aqüicultura correspondem à maior parcela dos custos totais de produção nas criações semi-intensivas (MEER et al., 1995), em função de as dietas para peixes possuírem elevado teor de proteína, em comparação às dietas para outros animais cultivados (FURUYA et al., 1997).

O farelo de soja (FS) é a fonte protéica de origem vegetal mais utilizada nas dietas para peixes, pela sua disponibilidade e valor nutritivo. Pelo seu elevado custo, têm-se buscado fontes protéicas alternativas que possam substituir, de forma parcial ou total, a sua proteína, em dietas para diversas espécies, nas diferentes fases de criação.

A canola, resultante do melhoramento genético da colza (Brassica napus e Brassica campestris), visando variedades que contenham menos de $2,00 \%$ de ácido erúcico no óleo e menos de $3,00 \mu \mathrm{g}$ de glicosinolatos por grama de matéria seca livre de óleo (SORREL e SHURSON, 1992; BAIDOO et al., 1996; FORSTER et al., 1999), é cultivada na região sul do Brasil durante o inverno. O farelo de canola é subproduto da indústria de óleo da semente de canola, possuindo perfil de aminoácidos comparável ao do FS

\footnotetext{
1 Programa de Pós-Graduação em Ecologia de Ambientes Aquáticos Continentais, Depto Biologia, Universidade Estadual de Maringá-UEM, Av. Colombo, 5790, Maringá-Paraná,87020-900. E.mail: cmsoares@uem.br

2 Prof. Dr., Depto. de Biologia, UEM, Av. Colombo, 5790, Maringá-PR. E.mail: chayashi@uem.br

3 Prof. Assistente, Depto. de Zootecnia, UEM, Av. Colombo, 5790, Maringá-PR. E.mail: furuya@wnet.com.br
} 
(MOREIRA et al., 1996), porém com níveis mais baixos de lisina e mais elevados de metionina + cistina (YURKOWSKI et al., 1978; SOARES et al., 2000).

Os altos teores de fibra bruta, a presença de metabólitos oriundos da hidrólise dos glicosinolatos (BELL, 1993; TESKEREDIZIC et al., 1995) e os inibidores de tripsina, fitatos (QUINTERO, 2000) e taninos (FURUYA et al., 1999) podem limitar sua utilização nas dietas para peixes. Os avanços nas áreas de melhoramento genético e processamento têm permitido maior inclusão de FC na alimentação animal. Entretanto, as pesquisas têm demonstrado grande variação nos resultados com a inclusão de FC nas dietas sobre o desempenho e utilização das dietas pelos peixes.

Algumas pesquisas utilizando o FC como substituto ao FS, como as de YURKOWSKI et al. (1978) com alevinos de truta, arco-íris (Oncorhynchus mykiss), FURUYA et al. (1997) com tilápia do Nilo, durante o período de reversão de sexo, e a de SOARES et al. (1998), com alevinos de carpa-capim (Ctenopharyngodon idella), demostraram que o emprego do FC, em substituição parcial ao FS, promove melhores índices de ganho de peso e conversão alimentar. Estes resultados são atribuídos a diferenças nos teores de aminoácidos destes alimentos, em que o uso de ambos possibilita a formulação de dietas com melhores perfis aminoacídicos.

Entretanto, alguns experimentos indicam que a substituição total da proteína do FS pela do FC ou a inclusão de altos níveis de FC nas dietas reduzem o desempenho dos animais, embora a taxa de sobrevivência não seja afetada. Isso foi observado por HILTON e SLINGER (1986), utilizando 40,00\% de FC em dietas para alevinos de Salmo gairdneri, DAVIES et al. (1990), com a inclusão de 30,00 a 60,00\% da dieta, em substituição à $\mathrm{FP}$, para alevinos de tilápia mossambica (Oreochromis mossambicus), e LIM et al. (1998), avaliando a inclusão do FC acima de 30,80\% da dieta para o bagre do canal (Ictalurus punctatus).

Por outro lado, segundo HARDY e SULLIVAN (1983), em dietas com 20,00\% de FC para o salmão ( $S$. gardineri), HIGGS et al. (1983), 23,00\% de FC em dietas para alevinos de $O$. tshawytscha em substituição à FP, e GALDIOLI et al. (2000), 32,00\% de FC em substituição ao FS em dietas para alevinos de curimbatá (Prochilodus lineatus), o FC não afetou o desempenho destes peixes. Destaca-se, ainda, a pesquisa de SOARES et al. (2000), em que o FC pode substituir totalmente o FS em dietas para alevinos de piavuçu (Leporinus macrocephalus), inclusive com melhora no desempenho.
As diferenças nos resultados obtidos, provavelmente, estão relacionadas com o conteúdo de fatores antinutricionais e a qualidade do farelo utilizado, uma vez que sua composição depende das condições de cultivo (características climáticas e tipo de solo), da variedade utilizada e da tecnologia no processamento empregado para a extração do óleo (QUINTERO, 2000). Outro fator a ser considerado são as características inerentes à espécie de peixes em questão, como o hábito alimentar. Poucas são as informações sobre a utilização do FC em dietas para peixes em crescimento, que podem contribuir para reduzir o custo com alimentação, uma vez que esse ingrediente possui custo inferior $( \pm 30,00 \%)$ ao do FS.

O presente experimento teve por objetivo avaliar os efeitos da substituição da proteína do farelo de soja pela proteína do farelo de canola sobre o desempenho e características de carcaça da tilápia do Nilo, na fase de crescimento.

\section{Material e Métodos}

O experimento foi realizado no período de 05 de dezembro de 1999 a 07 de março de 2000, nas instalações do Laboratório de Aqüicultura do Departamento de Biologia da Universidade de Estadual de Maringá. Foram utilizados 80 peixes com peso inicial médio de 22,19 $\pm 0,29 \mathrm{~g}$, distribuídos em 20 tanques em um delineamento em blocos casualizados.

Foram utilizados cinco tanques de concreto, divididos, cada um, em quatro tanques com capacidade para $200 \mathrm{~L}$, através de molduras com tela de nylon com malha de 1,00 $\mathrm{mm}$. Os tanques eram providos de aeração, com uma pedra porosa por unidade experimental, através de compressores e dois biofiltros internos (cano PVC de $10 \mathrm{~cm}$ de diâmetro e $80 \mathrm{~cm} \mathrm{de}$ altura) em cada tanque de concreto. Durante todo o período experimental, foi mantida a circulação de $25 \%$ do volume total de água de cada tanque por dia, sendo a entrada de água realizada em dois pontos na superfície de cada tanque de concreto e a saída realizada por um sifão instalado no fundo dos tanques, na parede oposta às entradas de água.

As dietas foram formuladas de acordo com as exigências propostas para a espécie pelo NATIONAL RESEARCH COUNCIL - NRC (1993), sendo as mesmas isocálcicas, isofosfóricas, isocalóricas e com 32,00\% de PB (Tabela 1). O FC foi incluído às dietas de forma a substituir 0,00 ; 33,$33 ; 66,67$ e $100,00 \%$, da proteína do FS, correspondendo às inclusões de 0,$00 ; 24,50 ; 49,00 \mathrm{e}$ 
1174 Rev. bras. zootec.

73,49\% do FC nas dietas, respectivamente.

Para a confecção das dietas, os ingredientes (milho, farinha de peixe, FS, FC e bagaço de cana) foram moídos individualmente em moinho tipo faca, com peneira de 1,00 mm de abertura. Após mistura manual dos ingredientes, as dietas foram umedecidas em água a $60^{\circ} \mathrm{C}$ e peletizadas em moinho de carne, sendo a desidratação das mesmas realizada em estufa de ventilação forçada a $55^{\circ} \mathrm{C}$, por 24 horas.

$\mathrm{O}$ arraçoamento foi realizado na proporção de

Tabela 1 - Composição percentual e química das dietas experimentais com diferentes níveis de substituição da proteína bruta do farelo de soja pela do farelo de canola (matéria natural) ${ }^{1}$

Table 1 - Chemical and percent composition of experimental diets with different dietary protein replacement level of soybean meal protein by canola meal protein (as feed) ${ }^{1}$

\begin{tabular}{|c|c|c|c|c|}
\hline \multirow[t]{2}{*}{$\begin{array}{l}\text { Ingrediente (\%) } \\
\text { Ingredient }\end{array}$} & \multicolumn{4}{|c|}{$\begin{array}{c}\text { Nível de substituição (\%) } \\
\text { Replacement level }\end{array}$} \\
\hline & 0,00 & 33,33 & 66,67 & 100,00 \\
\hline Milho & 24,69 & 22,68 & 20,67 & 18,66 \\
\hline $\begin{array}{l}\text { Corn } \\
\text { Farinha de peixe } \\
\text { Fish meal }\end{array}$ & 3,00 & 3,00 & 3,00 & 3,00 \\
\hline $\begin{array}{l}\text { Farelo de soja } \\
\text { Soybean meal }\end{array}$ & 62,13 & 41,42 & 20,71 & 0,00 \\
\hline $\begin{array}{l}\text { Farelo de canola } \\
\text { Canola meal }\end{array}$ & 0,00 & 24,50 & 49,00 & 73,49 \\
\hline $\begin{array}{l}\text { Bagaço de cana hidrolizado } \\
\text { Sugar cane bagasse }\end{array}$ & 1,90 & 1,48 & 1,07 & 0,65 \\
\hline $\begin{array}{l}\text { Calcário } \\
\text { Limestone }\end{array}$ & 0,00 & 0,13 & 0,26 & 0,39 \\
\hline $\begin{array}{l}\text { Fosfato bicálcico } \\
\text { Dicalcium phosphate }\end{array}$ & 2,64 & 2,06 & 1,57 & 1,04 \\
\hline $\begin{array}{l}\text { Óleo de soja } \\
\text { Soybean oil }\end{array}$ & 4,62 & 3,67 & 2,72 & 1,77 \\
\hline $\begin{array}{l}\text { Suplemento min. e vitam. } \\
\text { Min. vit. mixture }\end{array}$ & 0,50 & 0,50 & 0,50 & 0,50 \\
\hline $\begin{array}{l}\text { Sal comum } \\
\text { Common salt }\end{array}$ & 0,50 & 0,50 & 0,50 & 0,50 \\
\hline $\begin{array}{l}\text { BHT } \\
\text { Total }\end{array}$ & $\begin{array}{r}0,02 \\
100,00\end{array}$ & $\begin{array}{r}0,02 \\
100,00\end{array}$ & $\begin{array}{r}0,02 \\
100,00\end{array}$ & $\begin{array}{r}0,02 \\
100,00\end{array}$ \\
\hline Valores calculados & & & & \\
\hline $\begin{array}{l}\text { Calculated values } \\
\text { Energia digestível, } \mathrm{kcal} / \mathrm{kg}^{2} \\
\text { Digestible energy }\end{array}$ & 3200,00 & 3200,00 & 3200,00 & 3200,00 \\
\hline $\begin{array}{l}\text { Proteína bruta, } \% \\
\text { Crude protein }\end{array}$ & 32,00 & 32,00 & 32,00 & 32,00 \\
\hline $\begin{array}{l}\text { Lisina, \% } \\
\text { Lysine }\end{array}$ & 2,00 & 1,91 & 1,83 & 1,74 \\
\hline $\begin{array}{l}\text { Metionina + cistina, } \% \\
\text { Methionine + cystine }\end{array}$ & 1,10 & 1,18 & 1,27 & 1,36 \\
\hline $\begin{array}{l}\text { Cálcio, \% } \\
\text { Calcium }\end{array}$ & 1,03 & 1,03 & 1,03 & 1,03 \\
\hline $\begin{array}{l}\text { Fósforo disponível, \% } \\
\text { Disponible phosphorus }\end{array}$ & 0,55 & 0,55 & 0,55 & 0,55 \\
\hline $\begin{array}{l}\text { Fibra bruta, } \% \\
\text { Crude fiber }\end{array}$ & 5,00 & 5,70 & 6,40 & 7,11 \\
\hline $\begin{array}{l}\text { Extrato etéreo, } \% \\
\text { Ether extract }\end{array}$ & 6,43 & 5,62 & 4,81 & 4,00 \\
\hline
\end{tabular}

\footnotetext{
${ }^{1}$ Baseados nas análises de laboratório, realizadas para o milho, farelo de soja, farinha de peixe, farelo de canola, calcário e fosfato bicálcico (UEM/DZO).

2 Com base nos valores de energia digestível propostos para milho e farinha de peixe para a tilápia pelo NRC (1993), para o farelo de soja por PEZZATO (1995) e para farelo de canola pelo NRC (1993) para truta arco-íris e para o óleo de soja por SINTAYEHU et al. (1996)

1 Based on laboratory analysis of corn, soybean meal, fish meal, canola meal, limestone and dicalcium phosphate (UEM/DZO).

2 Based on proposed digestible energy values for corn and fish meal by tilapia by NRC (1993) and for soybean meal by PEZZATO (1995); and for canola meal by rainbow trout by NRC (1995) and for soybean oil by SINTAYEHU et al. (1996).
} 
3,00\% do peso vivo dia, sendo todos os peixes de cada unidade experimental pesados a cada dez dias, para a correção da quantidade a ser fornecida. Semanalmente, foram tomadas as medidas dos parâmetros $\mathrm{pH}$, condutividade elétrica e oxigênio dissolvido, enquanto a temperatura foi medida diariamente pela manhã $(8 \mathrm{~h})$ e pela tarde $(17 \mathrm{~h})$. Os valores da taxa de eficiência protéica foram calculados conforme a expressão de BELLAVER (1985).

Ao final do experimento, após jejum por dois dias, os peixes foram abatidos e eviscerados, para pesagem da carcaça (peixe isento de cabeça, vísceras, rastros branquiais, pele e nadadeiras, peitorais, pélvicas e dorsal), gordura visceral e fígado.

As análises estatísticas das variáveis foram realizadas por análises de variância e de regressão linear, por intermédio do programa SAEG Sistema de Análises Estatísticas e Genéticas descrito por EUCLYDES (1983). Os valores das características expressos em porcentagem foram transformados pela expressão $\mathrm{y}=\operatorname{arcsen}$, sendo $\mathrm{x}$ o valor da variável em porcentagem.

\section{Resultados e Discussão}

1175

Foram observados valores médios de $27,32 \pm 1,42^{\circ} \mathrm{C}$; $7 \pm 0,09 ; 168,81 \pm 4,13 \mu \mathrm{S} / \mathrm{cm} ; 4,1 \pm 1,49 \mathrm{mg} / \mathrm{L}$, respectivamente, para a temperatura, $\mathrm{pH}$, condutividade e oxigênio dissolvido da água. Estes apresentaram-se dentro dos limites descritos por SIPAUBA-TAVARES (1994), para os peixes tropicais.

Os valores médios de desempenho das tilápias do Nilo, alimentadas com as diferentes dietas, encontram-se na Tabela 2. Observou-se efeito quadrático $(\mathrm{P}<0,05)$ dos níveis de substituição da PB do FS pela do FC sobre a porcentagem de ganho de peso e rendimento de carcaça (Figura 1), em que foram obtidos os melhores valores com os níveis estimados de 48,17 (35,4\% inclusão de FC) e 45,93\% (33,76\% de inclusão de FC) de substituição da PB do FS pela do $\mathrm{FC}$, respectivamente.

Os maiores valores de porcentagem de ganho de peso e de rendimento de carcaça para os peixes alimentados com dietas que continham ambos os farelos, provavelmente, estão relacionados ao melhor

Tabela 2 - Valores médios de características de desempenho de tilápia do Nilo em fase de crescimento submetidas a dietas com diferentes níveis de substituição da proteína bruta do farelo de soja pela do farelo de canola ${ }^{1}$

Table 2 - Average performance values of growing Nile tilapia fed diets with different dietary protein replacement levels of soybean meal protein by canola meal protein ${ }^{1}$

\begin{tabular}{|c|c|c|c|c|c|}
\hline \multirow[t]{2}{*}{$\begin{array}{l}\text { Ingrediente (\%) } \\
\text { Ingredient }\end{array}$} & \multicolumn{4}{|c|}{$\begin{array}{c}\text { Nível de substituição (\%) } \\
\text { Replacementlevel }\end{array}$} & \multirow[b]{2}{*}{$\mathrm{CV}(\%)$} \\
\hline & 0,00 & 33,33 & 66,67 & 100,00 & \\
\hline $\begin{array}{l}\text { Peso médio inicial }(\mathrm{g}) \\
\text { Initial weight }\end{array}$ & 22,17 & 22,07 & 22,25 & 22,3 & 1,29 \\
\hline $\begin{array}{l}\text { Peso final médio }(\mathrm{g})^{1} \\
\text { Average final weight }\end{array}$ & 60,71 & 66,60 & 70,40 & 58,22 & 13,45 \\
\hline $\begin{array}{l}\text { Ganho de peso médio }(\%)^{2} \\
\text { Average weight gain }\end{array}$ & 173,64 & 201,94 & 216,72 & 160,99 & 20,97 \\
\hline $\begin{array}{l}\text { Conversão alimentar aparente } \\
\text { Apparent feed:gain ratio }\end{array}$ & 1,79 & 2,43 & 2,48 & 2,31 & 27,96 \\
\hline $\begin{array}{l}\text { Taxa de eficiência protéica } \\
\text { Protein efficiency ratio }\end{array}$ & 1,95 & 1,56 & 1,59 & 1,48 & 38,35 \\
\hline $\begin{array}{l}\text { Rendimento de carcaça }(\%)^{3} \\
\text { Carcass yield }\end{array}$ & 44,92 & 47,48 & 46,79 & 43,99 & 4,69 \\
\hline $\begin{array}{l}\text { Gordura visceral }(\%)^{4} \\
\text { Visceralfat }\end{array}$ & 0,51 & 0,54 & 0,37 & 0,36 & 36,93 \\
\hline $\begin{array}{l}\text { Índice hepato-somatico } \\
\text { Hepatic somatic factor }\end{array}$ & 1,46 & 1,44 & 1,40 & 1,51 & 21,77 \\
\hline
\end{tabular}

1 Efeito quadrático (Quadratic effect) $(\mathrm{p}<0,04)-\mathrm{Y}=60,0094+3,9590-0,0041 \mathrm{X}^{2} ; \mathrm{r}^{2}=0,56$

2 Efeito quadrático (Quadratic effect) $(\mathrm{p}<0,03)-\mathrm{Y}=170,7860+1,8222 \mathrm{X}-0,0189 \mathrm{X}^{2} ; \mathrm{r}^{2}=0,58$

3 Efeito quadrático (Quadratic effect) $(\mathrm{p}<0,04)-\mathrm{Y}=44,9749+0,1103 \mathrm{X}-0,0012 \mathrm{X}^{2} ; \mathrm{r}^{2}=0,76$

${ }^{4}$ Efeito linear (Linear effect) $(p<0,04)-Y=0,5400-0,0019 X ; r^{2}=0,61$ 
1176 Rev. bras. zootec.

balanceamento de aminoácidos nestas (MURAKAMI et al., 1996). O maior conteúdo de metionina do FC (YURKOWSKI et al. 1978; SOARES et al., 2000) foi o fator que mais contribuiu para esses resultados, uma vez que é o aminoácido mais limitante do FS.

Não foram observadas diferenças $(P>0,05)$ dos tratamentos para a conversão alimentar, taxa de eficiência protéica e índice hepato-somático. O resultado de conversão alimentar discorda de FURUYA et al. (1997), que observaram piora linear na conversão alimentar da tilápia do Nilo alimentada com dietas, contendo níveis crescentes de inclusão de FC. A piora no desempenho com os níveis mais elevados de substituição provavelmente está relacionada com os maiores conteúdos de ácido erúcico, taninos (BELL, 1993; QUINTERO, 2000) e fibra bruta nessas dietas.

QUINTERO (2000) observou que teores de taninos acima de $0,46 \%$ promovem redução na digestibilidade da matéria seca e da PB pela tilápia do Nilo e afetam ganho de peso de alevinos de piavuçu. Considerando-se os valores de taninos analisados por FURUYA et al. (1999), para o FC dessa mesma variedade, pode-se observar que a os tratamentos com níveis de substituição acima de $33,33 \%$ da PB do FS pela do FC resultaram em teores elevados de taninos, o que, juntamente com o aumento dos demais fatores antinutricionais, piorou o desempenho nesses tratamentos, confirmando os resultados encontrados por HILTON e SLINGER (1986), DAVIES et al. (1990) e LIM et al. (1998), com a truta arco-íris, tilápia mossambica e bagre do canal, respectivamente.

Foi observada redução linear $(\mathrm{P}<0,05)$ na porcentagem de gordura visceral à medida em que a $\mathrm{PB}$ do $\mathrm{FS}$ foi substituído pela do FC (Figura 1). Este resultado pode ser devido aos menores valores de extrato etéreo nas rações com teores mais elevados de FC e/ou pelos maiores níveis de taninos nessas dietas. Segundo QUINTERO (2000), os taninos reduzem a digestibilidade dos lipídios e, portanto, altera a relação proteína:energia.

Os resultados do presente estudo indicam que o uso de altos níveis de FC nas dietas acarretou em redução no desempenho doa tilápia do Nilo, o que pode ser devido à presença de diversos fatores antinutricionais que limitam a substituição total pela proteína do FC. No entanto, a possibilidade de substituição de aproximadamente 50,00\% da proteína do FS pode contribuir para reduzir os custos com alimentação, inclusive com melhora no desempenho dos animais.
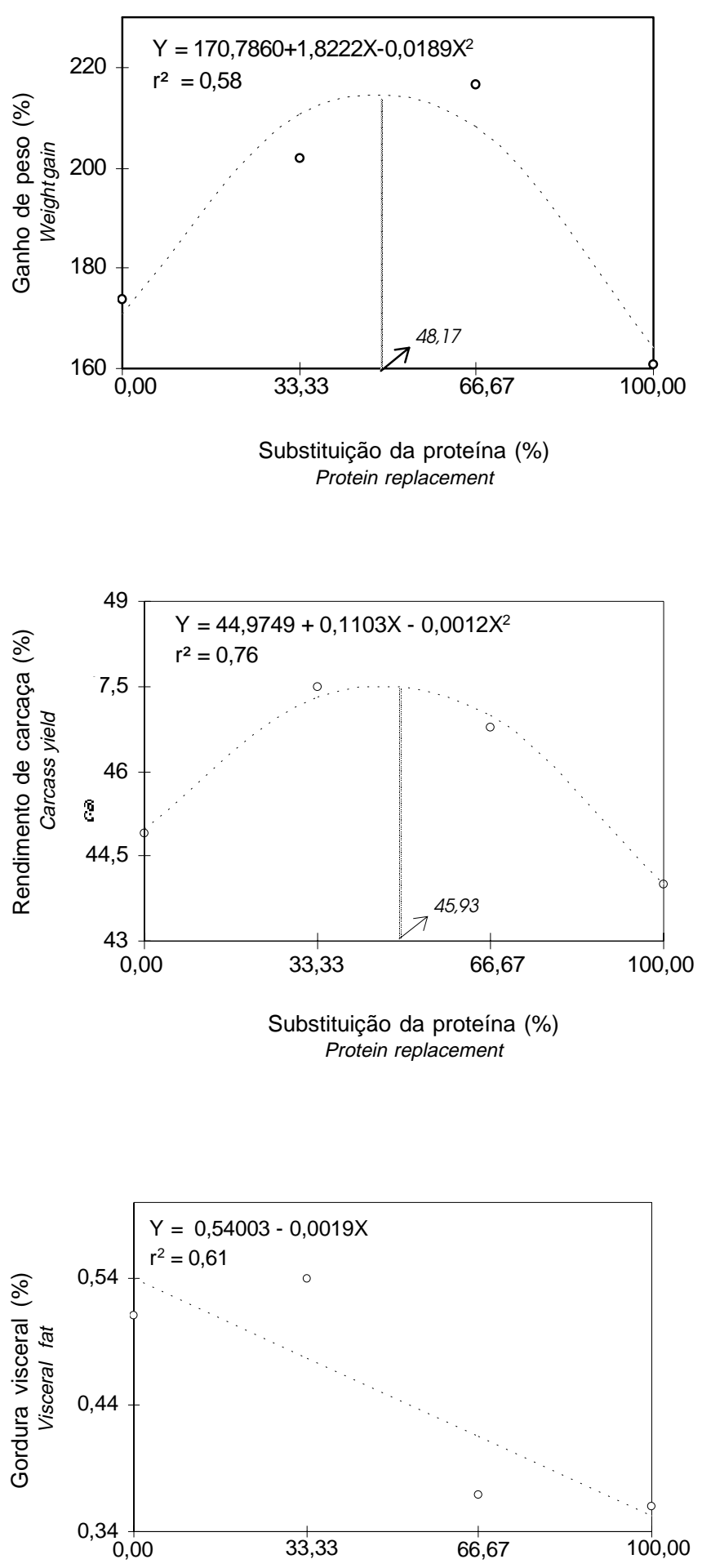
Substituição da proteína (\%)
Protein replacement

Figura 1 - Efeito dos níveis de substituição da proteína do farelo de soja pela do farelo de canola sobre a percentagem de ganho, rendimento de carcaça e gordura visceral de tilápia do Nilo.

Figure 1 - Effect of the dietary soybean protein replacement by canola meal protein on percent of weight gain, carcass yield and visceral fat of Nile tilapia. 


\section{Conclusões}

O farelo de canola pode ser incluído a 35,40\% (substituindo $48,17 \%$ da proteína do farelo de soja) em dietas para a tilápia do Nilo (Oreochromis niloticus), na fase de crescimento.

\section{Referências Bibliográficas}

BAIDOO, S.K., CLOWES, E.L., AHERNE, F.X. 1996. The digestible energy value of canola oil for growing pigs as measured by level inclusion. Anim. Feed Sci. Technology, 62(2/4): 111-119.

BELL, J.M. 1993. Factor affecting the nutritional value of canola meal: a review. J. Anim. Sci., 73(3):679-697.

BELLAVER, C., FIALHO, E.T., PROTAS, J.F.S. 1985. Radícula de malte na alimentação de suínos em crescimento e terminação. Pesq. Agropec. Bras., 20(8):969-974.

DAVIES, S.J., McCONNELL, S., BATESON, R.I. 1990. Potential of rapeseed meal as an alternative protein source in complete diets for tilapia (Oreochromis mossambicus Peters). Aquaculture, 87(1):145-154.

EL-SAYED, A.F.M. 1999. Alternative dietary protein sources for farmed tilapia, Oreochromis niloticus spp. Aquaculture Research, 179:149-168.

EUCLYDES, R.F. 1983. Manual de utilização do programa SAEG (Sistema para Análises Estatísticas e Genética). Viçosa: UFV.

FOSRSTER, I., HIGGS, A., DOSANJH, B.S et al. 1999. Potential for dietary phytase to improve the nutritive value of canola protein concentrate and decrease phosphorous output in rainbow trout (Oncorhynchus mykiss) held in $11^{\circ} \mathrm{C}$ fresh water. Aquaculture, 179:109-125.

FURUYA, W.M., PEZZATO, L.E., FURUYA, V.R.B. et al. 1999. Digestibilidade aparente da proteína e aminoácidos do farelo de canola para a tilápia do Nilo, Oreochromis niloticus. In: SOUTH AMERICAN AQUACULTURE CONGRESS, 2, 1999. Puerto de La Cruz. Anais... Puerto de La Cruz: WAS, 1999. v.1, p.206-217.

FURUYA, V.R.B., HAYASHI, C., FURUYA, W.M. 1997. Farelo de canola na alimentação da tilápia do Nilo (Oreochromis niloticus L.), durante o período de reversão de sexo. R. Bras. Zootec., 26(6):1067-1073.

GALDIOLI, E.M.; HAYASHI, C.; SOARES et al. 2000. Utilização de diferentes fontes protéicas na alimentação de alevinos de curimba (Prochilodus lineatus, V.). Acta Scientiarum, 22(2):471-477.

HARDY, R.W., SULLIVAN, C.V. 1983. Canola meal in rainbow trout (Salmo gairdneri) production diets. Can. J. Fisher. and Aquat. Sci., 40(3):281-286.

HIGGS, D.A., FAGERLUND, U.H.M., McBRIDE, J.R. et al. 1983. Protein quality of Altex canola meal for juvenile chinook salmon (Oncorhynchus tshawytscha) considering dietary protein and 3,5,3-triiodo-L thyonine content. Aquaculture, 34(3):213-238.

HILTON, J.W., SLINGER, S.J. 1986. Digestibility and utilization of canola meal in practical-type diets for rainbow trout (Salmo gairdneri). Can. J. Fisher. and Aquat. Sci., 43(6):1149-1155.

LIM, C., KLESIUS, P.H., HIGGS, D.A. 1998. Substitution of canola meal for soybean meal in diets for channel catfish Ictalurus punctatus. J. World Aquacut. Soc., 29(2):161-168.

LOVSHIN, L.L. Tilapia farming: A Growing Worldwide Aquaculture Industry. In: SIMPÓSIO SOBRE MANEJO E NUTRIÇÃO DE PEIXES, 1, 1997, Piracicaba. Anais... Piracicaba: CBNA, 1997. p.137-164.

MEER, M.B., MACHIELS, M.A.M., VERDEGEM, M.C.J. 1995. The effect of dietary protein level on growth, protein utilization and body composition of Colossoma macropomum (Cuvier). Aquaculture Research, 26(12):901-909.

MURAKAMI, A.E., KIRA, K.C., SCAPINELLO, C. et al. 1996. Farelo de canola na alimentação de poedeiras comerciais. R. Soc. Bras. Zootec., 24(3):401-408.

NATIONAL RESEARCH COUNCIL - NRC. 1993. Nutrients requirements of warmwater fishes and shellfishes. Washington: Academy Press. 102p.

PEZZATO, L.E. Alimentos convencionais e não-convencionais disponíveis para indústria da nutrição de peixes no Brasil. In: SIMPÓSIO INTERNACIONAL SOBRE NUTRIÇÃO E CRUSTÁCEOS, 1995, Campos de Jordão. Anais... Campos do Jordão, 1995. v.1, p.34-52.

QUINTERO, L.G.P. 2000. Tanino em rações para peixes tropicais. Jaboticabal SP: UNESP, 2000. 55p. Dissertação (Mestrado em Aquicultura) - Universidade Estadual Paulista, 2000.

SINTAYEHU, A., MATHIES, E., MEYER-BURFDORFF, K. H. 1996. Apparent digestibilities and growth experiment with tilapia (Oreochromis niloticus) fed soybean meal, cottonseed meal and sunflower seed meal. J. Appl. Ichthyol. Z. Angew. Ichthyol., 12(2):125-130.

SIPAUBA-TAVARES, V.L.S. 1994. Limnologia aplicada à aquicultura. Jaboticabal: FUNEP. 70p.

SOARES, C.M., HAYASHI, C., FURUYA, V.R.B. et al. 1998. Farelo de canola na alimentação de alevinos de carpa-capim (Ctenopharyngodon idella V.). Acta Scientiarum, (20)3:395-400.

SOARES, C.M., HAYASHI, C., FURUYA, W.M.B. et al. 2000. Substituição parcial e total da proteína do farelo de soja pela do farelo de canola na alimentação de alevinos de piavuçu (Leporinus macrocephalus, L.). Rev. bras. zootec., (20)3: 395-400.

SORREL, E.R., SHURSON, G.C. 1992. Use of canola and canola meal in swine diets reviewed. Feedstuffs, 62(14):s13-16.

TESKEREDIZIC, Z., HIGGS, D.A., DOSANJH, B.S. et al. 1995. Assessment of undephytinized and dephytinized rapeseed protein concentrate as sources of dietary protein for juvenile rainbow trout (Oncorhynchus mykiss). Aquaculture, 131(2): 261-277.

YURKOWSKI, M., BAILEY, J.K., EVANS, R.E., et al. 1978. Acceptability of rapeseed proteins in diets of rainbow trout (Salmo gairdneri). J. Fish Res. Board Can., 35: 951-962.

Recebido em: $18 / 10 / 00$ Aceito em: 22/03/01 